Заключение. По результатам исследований физико-механических свойств клубней картофеля сортов Волжанин и Невский можно сделать следующие выводы: вариационные кривые распределения массы клубней картофеля дают представление о фракционном составе вороха и позволяют судить о количественном составе фракций, подлежащих разделению; зависимости массы клубней от линейных размеров позволили определить в качестве рационального признака сортирования ширину клубня и размеры калибрующих отверстий правильной шестиугольной формы.

\section{СПИСОК ЛИТЕРАТУРЫ}

1. Миркина Е.Н., Бычкова Н.А. Техническое и хозяйственное назначение картофеля // Научная жизнь. - 2015. - № 5. - С. 21-27.

2. Миркина Е.Н., Левченко С.А. Физико-механические свойства клубней картофеля как объект калибрования // Научная жизнь. - 2014. - № 2. - С. 80-81.
3. Миркина Е.Н., Левченко С.А. Влияние угла наклона калибрующей поверхности на точность калибрования // Научное обозревание. - 2014. - № 1. - С. 48-49.

4. Миркина Е.Н. Обоснование процесса перемещения клубней картофеля по калибрующей поверхности // Научная жизнь. - 2014. - № 6. - С. 16-17.

5. Миркина Е.Н., Бычкова Н.А. Теоретическое обоснование процессов перемещения клубней картофеля по калибрующей поверхности, образованной правильными шестиугольниками // Аграрный научный журнал. - 2018. - № 1. - С. 55-58.

Миркина Елена Николаевна, канд. техн. наук, доиент кафедры «Инженерные изыскания, природообустройство и водопользование», Саратовский государственный аграрный университет имени Н.И. Вавилова. Россия.

410056, г. Саратов, ул. Советская, 60.

Тел.: (8452) 74-96-25.

Ключевые слова: клубень; масса клубня; толщина клубня; ширина клубня; длина клубня; способ разделения; сортирование клубней.

\title{
THE PHYSICAL AND MECHANICAL PROPERTIES OF POTATO TUBERS BY COMBINING TWO LINEAR DIMENSIONS
}

Mirkina Elena Nikolaevna, Candidate of Technical Sciences, Associate Professor of the chair "Engineering Survey, Environmental Management and Water Use", Saratov State Agrarian University named after N.I. Vavilov. Russia.

Keywords: tuber; weight of tuber; thickness of the tuber; width of the tuber; tuber length; method of separation; tuber sorting.
Some physical and mechanical properties of potato tubers and a method for dividing potato tubers into fractions are described by a combination of two linear dimensions width and thickness.

\section{ОБОСНОВАНИЕ СПОСОБА ОПРЕДЕЛЕНИЯ МАССЫ НАМОРОЖЕННОГО ЛЬДА}

\begin{abstract}
ПОПОВА Мария Игоревна, Оренбургский государственный аграрный университет КВАШЕННИКОВ Василий Иванович, Оренбургский государственный аграрный университет ШАХОВ Владимир Александрович, Оренбургский государственный аграрный университет КОЗЛОВЦЕВ Андрей Петрович, Оренбургский государственный аграрный университет АСТАФЬЕВ Артем Сергеевич, Оренбургский государственный аграрный университет
\end{abstract}

Задача о промерзании слоя воды может быть сформулирована как задача о сопряжении двух температурных полей на движущемся фронте промерзания, то есть, сведена к решению уравнений теплопроводности. Данные расчеты показывают, что значение температуры льда определяется главным образом величиной коэффициента теплоотдачи от льда к воздуху. Но значение этого коэффициента сильно варьирует в зависимости от метеоусловий (скорость ветра, влажность воздуха, атмосферное давление, состояние поверхности льда и т.д.).

Введение. Для использования водного льда как аккумулятора природного холода широко распространен способ его получения путем заполнения водой различных емкостей с их последующим замораживанием $[6,7,8]$. В таких случаях всегда возникает проблема контроля процесса с целью определения динамики намораживания ледяной массы и принятия мер для предотвращения разрушения стенок емкостей (размораживания).

Вода - единственное вещество в природе, обладающее сразу двумя аномальными свойствами [10] . 
1. У всех веществ при охлаждении жидкой фазы плотность увеличивается вплоть до температуры затвердевания. При достижении этой температуры жидкость твердеет сразу во всем объеме подобно бетонному раствору.

У воды при охлаждении от $20{ }^{\circ} \mathrm{C}$ плотность возрастает только до $4{ }^{\circ} \mathrm{C}$. При дальнейшем охлаждении вплоть до температуры затвердевания (замерзания), т.е. до $0{ }^{\circ} \mathrm{C}$, плотность не увеличивается, а уменьшается. Это приводит к тому, что затвердевать вода начинает не сразу во всем объеме, а с образования ледяной корочки. С течением времени толщина ледяной корочки увеличивается, а температура воды под ней остается постоянной $\left(0{ }^{\circ} \mathrm{C}\right)$ при любой отрицательной температуре воздуха. И пока вся вода не превратится в лед, ее температура будет $0{ }^{\circ} \mathrm{C}$. Только после этого температура льда начнет снижаться, приближаясь к температуре морозного воздуха $[1-4,9]$.

2. У всех веществ твердая фаза тяжелее жидкой. Кусок любого твердого вещества тонет в расплавленной массе этого вещества. Твердая фаза (лед) не тонет в жидкой, а плавает на поверхности воды.

Плотность воды $\rho_{\text {в }}$ и льда $\rho_{\text {л }}$ при температуре затвердевания $\left(0{ }^{\circ} \mathrm{C}\right)$ составляет $\rho_{\mathrm{B}}=999,8 \mathrm{\kappa г} / \mathrm{M}^{3}$, $\rho_{\text {л }}=916,8$ кг $/ \mathrm{M}^{3}$.

Из-за наличия названных аномальных свойств объем льда $V_{\text {л }}$ всегда больше объема воды $V_{\text {в }}$, из которой он образовался:

$$
V_{\text {л }}-V_{\mathrm{B}}=\Delta V .
$$

Возникновение $\Delta V$ в любом замкнутом объеме вызывает в нем давления в сотни МПа, что является причиной разрушения (размораживания) ограничивающей этот объем поверхности. Чем больше масса льда, тем больше $\Delta V$, тем больше давление внутри этого объема.

методика исследований. Процесс образования льда в любой открытой емкости всегда начинается с верхнего, открытого слоя, так как имеет прямой контакт с морозным воздухом. Образование льда на боковой и донной поверхностях емкости происходит несколько медленнее, так как теплообмен с морозным воздухом осуществляется через стенку емкости, оказывающей сопротивление переносу теплоты от воды к морозному воздуху.

Величина теплового сопротивления зависит от теплофизических свойств стенки (толщины, коэффициента теплопроводности материала стенки, формы поверхности и т.д.). Поэтому любых открытых, как и в закрытых емкостях с водой процесс образования льда всегда происходит внутри замкнутого объема.

Логично предположить, что если воду объемом $\Delta V$ удалять из замкнутого объема с замерзающей водой, то не произойдет разрушения ограничивающей поверхности.
Результаты исследований. Из формулы (1)видно, что $\Delta V$ имеет связь с объемом льда $V_{\text {л }}$. Эту связь можно выявить из следующих соображений: $M_{\text {л }}=M_{\mathrm{B}}$, а значит, справедливо равенство $V_{\text {л }} \rho_{\text {л }}=V_{\text {в }} \rho_{\text {в }}$. Из этого следует:

$$
V_{\mathrm{\pi}}=V_{\mathrm{B}}^{\frac{\rho_{\mathrm{g}}}{\rho_{\mathrm{s}}}},
$$

где $M_{л}$ - масса льда, кг; $M_{\text {в }}$ масса воды, кг, которая превратилась в лед.

В уравнении (2) $\frac{\rho_{\mathrm{g}}}{\rho_{\pi}}$ есть отношение удельного объема льда $v л$ к удельному объему воды $v_{\mathrm{B}}$. Удельный объем - объем, занимаемый единицей массы вещества, физическая величина, обратная плотности, если плотность равная $\rho$, то удельный объем $\frac{1}{\rho}$. Следовательно:

$$
\frac{v_{\pi}}{v_{B}}=\frac{1}{\rho_{\pi}}: \frac{1}{\rho_{\mathrm{B}}}=\frac{\rho_{\mathrm{B}}}{\rho_{\pi}} .
$$

Численное Значение $\frac{\rho_{\mathrm{g}}}{\rho_{\Omega}}=\frac{999,8 \mathrm{kr} / \mathrm{m}^{8}}{916,8 \mathrm{kr} / \mathrm{m}^{8}}=$
$=1,0905322$.

Это соотношение отвечает на вопрос, во сколько раз объем льда больше объема воды, из которой он образовался? Ответ - в 1,0905322 раза.

Подставив значение $V_{\text {л }}$ из формулы (2) в формулу (1), получим:

$$
\begin{gathered}
V_{\mathrm{B}} \frac{\rho_{\mathrm{B}}}{\rho_{\pi}}-V_{\mathrm{B}}=\Delta V ; \\
\mathrm{V}_{\mathrm{B}}\left(\frac{\rho_{\mathrm{B}}}{\rho_{\pi}}-1\right)=\Delta V ; \\
\frac{V_{\mathrm{B}}\left(\rho_{\mathrm{B}}-\rho_{\pi}\right)}{\rho_{\pi}}=\Delta V .
\end{gathered}
$$

Умножая числитель и знаменатель левой части уравнения (5) на $\rho_{\mathrm{z}}$, получим:

$$
\frac{V_{\mathrm{B}} \rho_{\mathrm{B}}\left(\rho_{\mathrm{B}}-\rho_{\pi}\right)}{\rho_{\pi} \rho_{\mathrm{B}}}=\Delta V .
$$

В формуле (6)

$$
V_{\mathrm{B}} \rho_{\mathrm{B}}=M_{\mathrm{B}}=M_{\text {л }} .
$$

Выражение $\frac{\rho_{\mathrm{g}}-\rho_{\pi}}{\rho_{\mathrm{B}} \rho_{\pi}}$ представляет собой разность удельных объемов льда $v_{\pi}$ и воды $v_{\mathrm{B}}$, т.е. $\Delta v$.

$$
\Delta v=v_{\pi}-v_{\mathrm{g}}=\frac{1}{\rho_{\pi}}-\frac{1}{\rho_{\mathrm{g}}}=\frac{\rho_{\mathrm{g}}-\rho_{\pi}}{\rho_{\mathrm{B}} \rho_{\pi}}
$$

$$
\begin{aligned}
& \text { Числовое значение } \Delta v=\frac{999,8-916,8}{999,8 \cdot 916,8}= \\
& =9,0550396 \cdot 10^{-5} \mathrm{M}^{3} / \text { кг. }
\end{aligned}
$$

Величина $\Delta v$ отвечает на вопрос: на сколько удельный объем льда $\frac{1}{\rho_{л}}$ больше удельного объема воды $\frac{1}{\rho_{\mathrm{g}}}$, из которой этот лед образовался. Ответ - на 9,0550396 $10^{-5} \mathrm{M}^{3} /$ кг.

У всех веществ, встречающихся в природе в жидком и твердом состоянии, $\frac{1}{\rho_{\text {тв }}}-\frac{1}{\rho_{ж}}<0$, где $\rho_{\text {тв }} ; \rho_{\text {ж }}$ соответственно плотность твердой и жидкой фаз вещества. Только у воды эта разность больше нуля. 
С учетом уравнений (7) и (8) формула (6) примет следующий вид:

$$
M_{\mathrm{\pi}} \Delta \mathrm{v}=\Delta V ; M_{\text {л }}=\frac{1}{\Delta \mathrm{v}} \Delta V .
$$

С учетом того, что $\Delta v$ - величина постоянная, вычислим числовое значение дроби $\frac{1}{\Delta v}$ :

$$
\frac{1}{\Delta v}=\frac{1}{9,0550396 \cdot 10^{-5} \mathrm{M}^{\mathrm{s}} / \mathrm{kr}}=11043,57 \mathrm{\kappa} \Gamma / \mathrm{M}^{3} .
$$

Округляя, принимаем $\frac{1}{\Delta v}=11044$ кг/ $\mathrm{M}^{3}$. Обозначим $\frac{1}{\Delta v}$ символом $\ll k »$.

Тогда уравнение (9) примет следующий вид:

$$
M_{\text {л }}=k \Delta V .
$$

Коэффициент «k» является количественной характеристикой аномальных свойств воды, назовем его коэффициентом аномальности воды.

Формула (10) справедлива при условии, что весь объем $\Delta V$, удаленный из емкости, возвращается в эту емкость, разливаясь по поверхности льда с последующим замерзанием. Если возврата $\Delta V$ не будет, то масса льда в емкости $M_{\text {л }}^{\prime}$ окажется меньше на величину $\Delta V \rho_{\mathrm{\varepsilon}}$. Тогда $M_{\text {л }}^{\prime}=k \Delta V-\rho_{\mathrm{s}} \Delta V$. После преобразований и подстановки численных значений «k» и «Р $\rho_{\mathrm{z}}$ масса льда $M_{\text {л }}^{\prime}$ будет равна:

$$
M_{\text {л }}^{\prime}=1044 \Delta V .
$$

Объясним вышеизложенное на следующем примере. Возьмем большой бесформенный кусок льда неизвестного происхождения (из реки, бассейна и т.д.). Взвесим его с целью определения массы. Пусть масса льда оказалась, например, 20 кг. Не забудем, что эти 20 кг льда образовались из 20 кг воды.

Вычислим объем, занимаемый 20 кг льда $V_{\text {л }}$, и объем 20 кг воды, из которой этот лед образовался, $V_{\text {в }}$.

$V_{\text {л }}=20 \kappa г: 0,9168$ кг $/$ л $=21,815008$ л;

$V_{\text {в }}=20 \kappa г: 0,9998$ кг $/$ л $=20,004$ л.

Разность объемов $V_{\text {л }}-V_{\text {в }}=\Delta V=21,815-$ $-20,004=1,811$ л.

Если бы этот лед образовался в баке с неизвестным объемом воды $X$ л, то после образования льда общий объем в баке (вода + лед) оказался бы равным $(X+1,811)$ л. Но «лишний» объем 1,811 л в силу описанных выше причин был бы выдавлен (вытеснен) из бака, если бак оборудован устройством для отвода этой «лишней» воды. Если такого устройства нет, то бак разрушится.

Соберем вытесненный объем воды и, поместив его в мерную емкость, убедимся, что он равен 1,811 л.

Пересчитаем массу льда, приходящуюся на 1 л вытесненной воды.

На 1,811 л приходится 20 кг льда;

на 1 л - X кг льда.
$X=\frac{20 \cdot 1}{1,811}=11,043573$ кг/л (кг льда на 1 л вытесненной воды).

Данный опыт можно проделывать многократно, задаваясь различной массой намороженного льда, например, 10 кг; 35 кг; 17 кг и т.д. При этом разность $V_{\text {л }}-V_{\text {в }}$ окажется равной 0,9055 ; 3,$16926 ; 1,53936$ л соответственно и т.д.

Но каждый раз при пересчете массы льда, приходящейся на 1 л вытесненной (лишней) воды «k», будет иметь одно и то же числовое значение 11,043573 кг/л. Эта величина постоянна для воды. Она является числовой характеристикой аномальных свойств воды.

Данное утверждение справедливо для любых емкостей, в том числе с нетеплоизолированными стенками, в которых лед образуется и на боковой, и на донной поверхности.

Разумеется, если размерность «кг/л» пересчитать на другие объемные единицы, то коэффициент «k» будет иметь следующие значения 11043,573 кг $/ \mathrm{M}^{3}, 11,043$ г $/ \mathrm{cm}^{3}$. Для практических расчетов можно пользоваться округленными значениями этих величин.

Приведенный пример показывает, что для определения массы льда, образовавшегося в какойлибо емкости на данный момент времени, нет необходимости знать численное значение объема воды в емкости $\left(X_{\pi}\right)$, форму и геометрические размеры емкости, теплофизические свойства материала стен этой емкости. Надо знать только одну величину - численное значение $\Delta V$.

Поясним это утверждение схемой прибора, позволяющего отводить и измерять объем $\Delta V$, вытесняемый из сосуда с замерзающей водой (рис. 1).

Если окажется, что $\Delta V_{1}=\Delta V_{2}=\Delta V_{3}=\Delta V$ (см. рис. 1), то масса льда во всех трех емкостях одинакова и равна $\mathrm{M}=11,044$ кг $/ л \cdot \Delta V$ л. Если $\Delta V_{1} \neq \Delta V_{2} \neq \Delta V_{3}$, то в каждой емкости масса льда будет различна. Ее можно вычислить по формуле (10).

Вместимость сосуда с гибкой стенкой $V_{\text {сос }}$ можно определить из соотношения (4).

$$
V_{\text {сос }} \geq 0,0905322 V_{\text {B }} \text {. }
$$

Однако использовать способ, показанный на рис. 1, и устройство для предохранения стенок емкостей от разрушения при намораживания льда имеет смысл только для сосудов до 5 л.

При намораживании льда в больших емкостях (бак, бассейн, цистерна и т.д.) необходимы иные технические решения, позволяющие непрерывно отводить воду объемом $\Delta V$ из замкнутого объема емкости и периодически, после измерения численного значения $\Delta V$, возвращать эту воду в емкость [8], разливая ее тонким слоем по поверхности намороженного льда [3, 8]. При этом все закономерности, описанные выше, остаются в силе. 


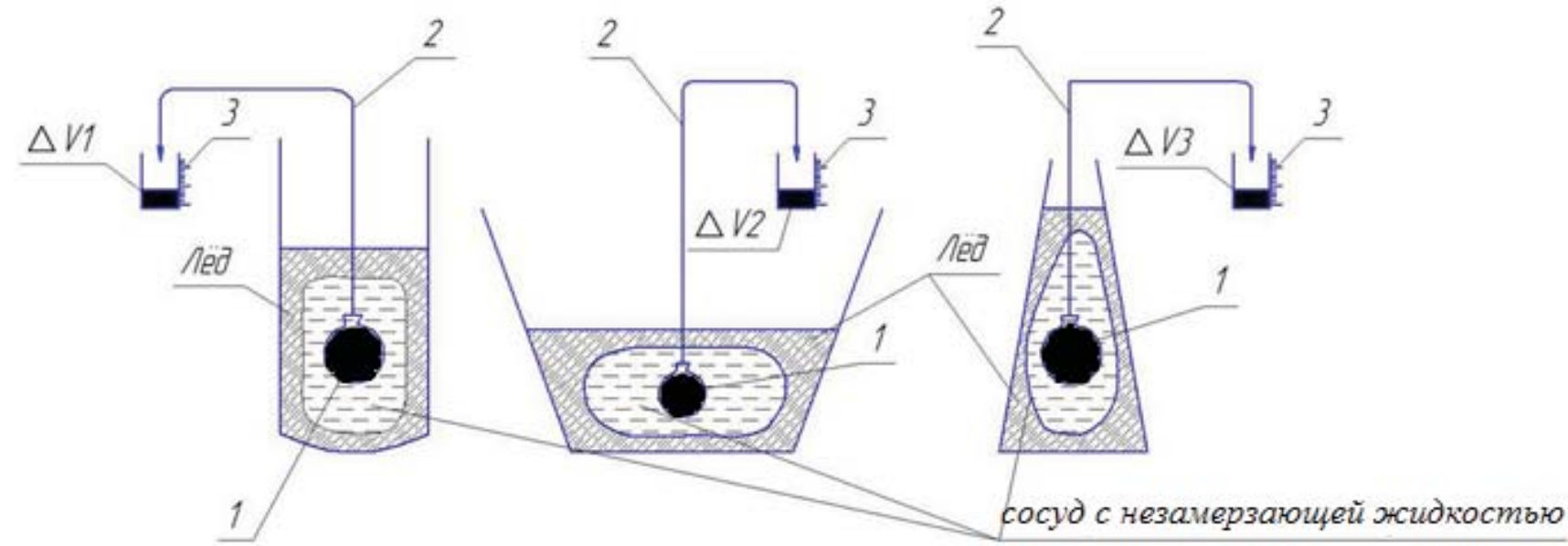

Рис. 1. Схема емкостей различной формы и различной заполненности для замораживания воды: 1 - сосуд с незамерзающей жидкостью; 2 - дренажная трубка; 3 - икала

Максимальное суммарное значение $\Delta V$, получающееся при полном замерзании емкости объемом «X», следует вычислять по формуле (4).

Так, например, при полном замерзании бассейна $X=100 \mathrm{M}^{3}$ суммарное значение $\Delta V$ составит $100 \mathrm{M}^{3} \cdot 0,0905322=9,05322 \mathrm{M}^{3}$, или 9053,22 л.

Теоретические положения о возможности использования объема $\Delta \mathrm{V}$ для предохранения стен емкостей от разрушения при намораживании льда и расчета массы льда в емкости были подтверждены экспериментально.

Две стеклянные 2-литровые емкости, заполненные водой, были размещены на открытом воздухе с температурой $-20^{\circ} \mathrm{C}$. В емкость 1 вставлено пластичное предохранительное устройство (3) в форме груши с отводящей дренажной трубкой (4) (рис. 2). Предохранительное устройство заполнили техническим незамерзающим раствором до $-30{ }^{\circ} \mathrm{C}$. В емкости 2 предохранительного устройства нет.

После 24 ч пребывания емкостей на морозном воздухе вода в них полностью замерзла. Из емкости 1 вытеснено 175 мл незамерзающего раствора. Целостность емкости при этом не нарушена. Емкость 2 (рис. 3) полностью разрушена.

Расчетная масса льда в емкости 1 определена по формуле $\mathrm{M}_{\text {л }}=k \Delta V=$ $=\frac{11,044 \mathrm{kr}}{\pi} \cdot 0,175 \pi=1,932 \mathrm{kr} . \quad$ Фактическая масса льда, определенная путем взвешивания, оказалась равной 2,01 кг. Ошибка опыта составила $3,9 \%$, что свидетельствует о хорошей сходимости расчетных и опытных данных о числовом значении массы намороженного льда.

Заключение. Вследствие аномальных свойств вода при замерзании увеличивается в объеме в 1,0905322 раза, что является причиной разрушения (размораживания) стенок емкостей с замершей водой. В момент, когда разность объемов $V_{\text {л }}-V_{\text {в }}$ равна 1 л, масса намороженного льда в емкости всегда оказывается равной 11,044 кг

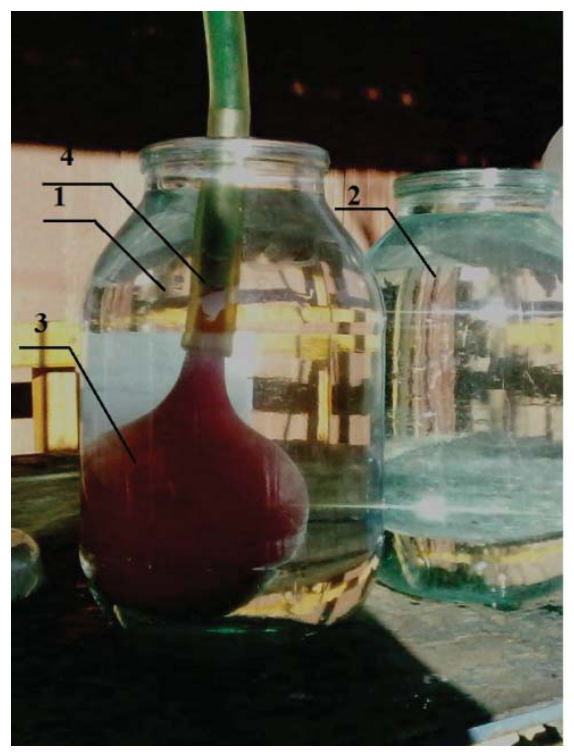

Рис. 2. Емкости перед началом эксперимента: 1 - емкость, оснащенная предохранительным устройством; 2 - емкость, не оснащенная предохранительным устройством; 3 - предохранительное устройство; 4 - дренажная трубка

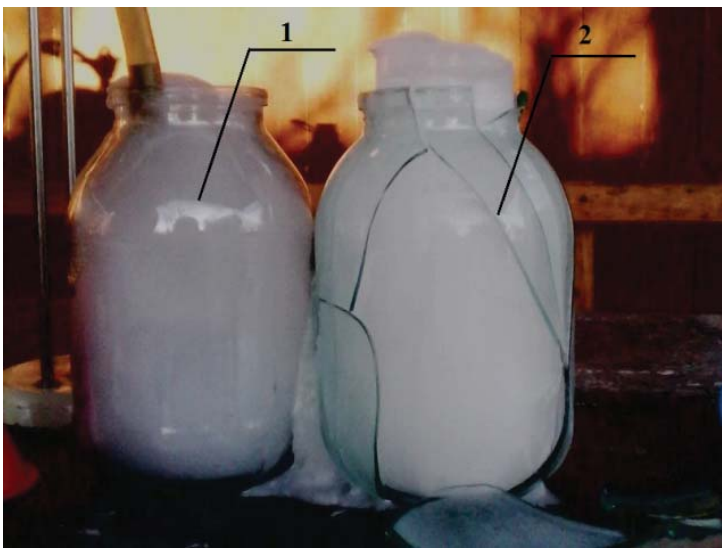

Рис. 3. Емкости после эксперимента: 1 - емкость, оснащенная предохранительным устройством; 2 - емкость, не оснащенная предохранительным устройством 
(округленно). Данное числовое значение является количественной мерой аномальных свойств воды. Ее размерность «кг/л», условное обозначение «k». В пересчете на другие объемные единицы коэффициент «k» будет иметь следующие величины: 11044 кг $/ \mathrm{M}^{3}, 11,044$ г $/ \mathrm{cm}^{3}$.

Текущее числовое значение разности объемов $\Delta V\left(\mathrm{M}^{3}, \pi\right)$ позволяет вычислить массу льда, образовавшегося в емкости на данный момент времени, независимо от количества незамерзшей воды, формы и размеров емкости $M_{\text {л }}=k \Delta V$.

Техническое устройство, позволяющее удалять незамерзающую жидкость из емкостей с замерзающей водой, с одновременным измерением разности объемов $\Delta V$ в объемных единицах, является счетчиком - предохранителем льдоккумуляторов водного льда.

\section{СПИСОК ЛИТЕРАТУРЫ}

1. Бобков В.А. Производство и применение льда. М.: Пищ. пром-сть, 1977. - 230 с.

2. Бузин В.А., Зиновъев А.Т. Ледовые процессы и явления на реках и водохранилищах. - Барнаул: ООО «Пять плюс», 2009. - 167 с.

3. Круглогодовое использование природного холода в условиях молочно-товарных ферм Южного Урала: рекомендации / А.И. Завражнов [и др.]. - Мичуринск, 2016. - 61 с.

4. Природный холод - приоритетное направление при охлаждении молока / А.П. Козловцев [и др.] // Известия Оренбургского ГАУ. Теоретический и научно-практический журнал. - 2015. - № 6 (56). C. 90-93.

5. Патент на изобретение № 2561745 РФ. Хранилище для пищевых продуктов с аккумулированием холода/ В.И. Квашенников, А.П. Козловцев, В.А. Шахов, Г.С. Коровин, А.А. Панин, И.В. Герасименко. Опуб. 10.09.2015.

6. Патент на изобретение №2627574 РФ. Установка для послойного намораживания и ис- пользования природного льда при охлаждении молока. В.И. Квашенников, А.П. Козловцев, В.А. Шахов, М.И. Попова, И.В. Герасименко. Опуб. 08.08.2017.

7. Пиотрович В.В. Расчеты толщины ледяного покрова на водохранилище по метеорологическим данным. -Л.: Гидрометеоиздат, 1968. - 186 с.

8. Хилькевич С.С. Физика вокруг нас. - М.: Наука, 1985. - 159 c.

9. Терминология при производстве и эксплуатации ледогенераторов / В.И. Квашенников [и др.] // Механизация и электрификация сельского хозяйства. - 2014. - №2. - С. 30-31.

10. Энергосберегающий метод охлаждения молочной продукции / В.И. Квашенников [и др.] // Известия ОГАУ. - 2013. - № 3. - С. 97.

Попова Мария Игоревна, аспирант кафедры «Механизация технологических процессов в АПК», Оренбургский государственный аграрный университет. Россия.

Квашенников Василий Иванович, $\partial-p$ техн. наук, проф. кафедры «Механизация технологических процессов в АПК», Оренбургский государственный аграрный университет. Россия.

Шахов Владимир Александрович, $\partial-p$ техн. наук, проф. кафедры «Механизация технологических процессов в АПК», Оренбургский государственный аграрный университет. Россия.

Козловцев Андрей Петрович, $\partial-p$ техн. наук, доцент, зав. кафедрой «Механизация технологических процессов в АПК», Оренбургский государственный аграрный университет. Россия.

Астафьев Артем Сергеевич, бакалавр, Оренбургский государственный аграрный университет. Россия.

460795, г. Оренбург, ул. Челюскинцев, 18.

Тел.: (3532) 77-52-30.

Ключевые слова: водный лед; замораживание воды; плотность; удельный объем; аномальные свойства воды.

\section{JUSTIFICATION OF THE METHOD FOR DETERMINING THE MASS OF FROZEN ICE}

Popova Mariya Igorevna, Post-graduate Student of the chair "Mechanization of Technological Processes in the Agro-industrial Complex", Orenburg State Agrarian University. Russia.

Kvashennikov Vasiliy Ivanovich, Doctor of Technical Sciences, Professor of the chair "Mechanization of Technological Processes in the Agro-industrial Complex”, Orenburg State Agrarian University. Russia.

Shakhov Vladimir Aleksandrovich, Doctor of Technical Sciences, Professor of the chair "Mechanization of Technological Processes in the Agro-industrial Complex”, Orenburg State Agrarian University. Russia.

Kozlovtsev Andrey Petrovich, Doctor of Technical Sciences, Associate Professor, Head of the chair "Mechanization of Technological Processes in the Agro-industrial Complex”, Orenburg State Agrarian University. Russia.
Astafyev Artem Sergeevich, Bachelor, Orenburg State Agrarian University. Russia.

Keywords: water ice; freezing of water; density; specific volume; abnormal properties of water.

The problem offreezing of the water layer can be formulated as the problem of pairing of the two temperature fields on a moving freezing front, i.e. reduced to solving equations of heat conductivity. These calculations show that the temperature of the ice is determined mainly by the value of the coefficient of heat transfer from ice to air. But the value of this coefficient varies strongly depending on weather conditions (wind speed, humidity, barometric pressure, condition of the ice surface, etc.). 